\title{
DEVELOPMENT OF COMPETITION IN REGIONAL MARKETS OF MEDICAL SERVICES
}

\author{
Olga Yu. Gorbova \\ Ryazan State Radio Engineering University, Ryazan, Russian Federation
}

\begin{abstract}
The purpose of assessing the level of competition in the market of medical services is achieved through the use of the author's methodology. The author develops a theoretical model of competition taking into account features of the social sphere on the basis of the received estimates. The method of assessing the level of competition includes two groups of indicators: objective and subjective ones. Objective indicators are based on the use of official statistical information, subjective indicators are based on the data of electronic surveys of service consumers. The paper presents the integral assessment in points and allows to refer the level of competition in the market to one of three categories: weak, moderate or strong competition. According to the results of evaluating, the author points out the problems hindering the development of competition in the market, as well as features that impose restrictions on the potential of forming a competitive environment. These include: high share of public institutions in the market, complexity of working in the system of compulsory health insurance for commercial organizations, lack of real mechanisms for the development of competition on the part of the state. The author presents a theoretical model of development of competition in the market including three levels of medical organizations allocated in accordance with complexity and cost of the process of providing services and conditions implemented by Federal and regional authorities.

Key words: health care, market of medical services, methodology of assessing competition, development of competition in medicine, indicators of competition development.

Citation. Gorbova O.Yu. Development of Competition in Regional Markets of Medical Services. Journal of Volgograd State University. Economics, 2019, vol. 21, no. 3, pp. 97-106. (in Russian). DOI: https://doi.org/10.15688/ ek.jvolsu.2019.3.9
\end{abstract}

УДК 332.14

Дата поступления статьи: 18.04.2019

ББК 65.495

Дата принятия статьи: 31.05.2019

\section{РАЗВИТИЕ КОНКУРЕНЦИИ НА РЕГИОНАЛЬНЫХ РЫНКАХ МЕДИЦИНСКИХ УСЛУГ}

\author{
Ольга Юрьевна Горбова \\ Рязанский государственный радиотехнический университет, г. Рязань, Российская Федерация
}

\begin{abstract}
Аннотация. Целью данной статьи является оценка уровня конкуренции на рынке медицинских услуг с использованием авторской методики и разработка теоретической модели ее развития с учетом особенностей социальной сферы. Методика оценки уровня конкуренции включает в себя две группы показателей: 1) объективные, основанные на использовании официальной статистической информации; 2) субъективн. ные, построенные на данных электронных опросов потребителей услуг. Интегральная оценка представлена в 글 баллах и позволяет отнести уровень конкуренции на рынке к одной из трех категорий: слабой, умеренной или ○ं сильной конкуренции. По итогам оценки выявлены проблемы, препятствующие развитию конкуренции на рынке, а также особенности, накладывающие ограничения на потенциальные возможности формирования конкурентной среды. К ним относятся: высокая доля государственных учреждений на рынке, сложности работы в системе обязательного медицинского страхования для коммерческих организаций, отсутствие реальных механизмов развития конкуренции со стороны государства. Автором предложена теоретическая () модель развития конкуренции на рынке, которая включает три уровня медицинских организаций, выделен-
\end{abstract}


ных в соответствии со сложностью и затратностью процесса оказания услуг, и условия, реализуемые федеральными и региональными органами власти.

Ключевые слова: здравоохранение, рынок медицинских услуг, методика оценки конкуренции, развитие конкуренции в медицине, показатели развития конкуренции.

Цитирование. Горбова О. Ю. Развитие конкуренции на региональных рынках медицинских услуг // Вестник Волгоградского государственного университета. Экономика. - 2019. - Т. 21, № 3. - С. 97-106. - DOI: https://doi.org/10.15688/ek.jvolsu.2019.3.9

\section{Введение}

Сфера здравоохранения в последние десятилетия претерпела множество изменений. При этом основным ориентиром развития отрасли стали лозунги о формировании конкуренции на рынке медицинских услуг. Очередным этапом в данном направлении явилось принятие Стандарта развития конкуренции в субъектах РФ в 2015 г., когда рынок медицинских услуг вошел в число социально значимых рынков регионов [Стандарт ...]. Национальный план развития конкуренции, утвержденный Указом Президента РФ от 21.12.2017 № 618, также содержит упоминание рынка медицинских услуг в составе отрасли, в которой необходимо развивать конкуренцию [Об основных направлениях ...].

За последние два десятилетия уже были попытки построения хотя бы теоретической модели функционирования российского здравоохранения в условиях конкуренции. Среди научных работ определенный интерес представляют труды И.А. Тогунова, В.Д. Селезнева, С.Д. Волкова, И.Н. Баранова и других исследователей. Большинство изысканий свидетельствуют о том, что конкуренция в рассматриваемой сфере не может пониматься традиционным образом и даже у этого понятия есть особенности применительно к медицине. В частности, в работах И.А. Тогунова конкуренция в сфере здравоохранения понимается как «состояние и процесс взаимоотношений субъектов производства и потребления медицинских услуг в рамках специфической цивилизованной формы соперничества между медицинскими работниками (врачами) по достижению наивысшей степени удовлетворения целевых потребностей пациента» [Тогунов, 2007, с. 111]. Очевидной целью конкурентной борьбы в данном случае является удовлетворение потребностей пациента.
В работе В.Д. Селезнева и С.Д. Волкова, конкуренция поставщиков медицинских услуг понимается как «их соперничество, направленное на достижение желаемых результатов деятельности в условиях меняющихся ограничений. Ограничения касаются различных сторон деятельности, начиная с доступа к ресурсам и кончая возможностью влиять на те или иные государственные структуры» [Ceлезнев и др., 2016]. В данном случае речь об удовлетворении потребностей пациента уже не идет и основной акцент деятельности медицинских организаций смещается на получение прибыли.

Кроме приведенных кардинальных взглядов на конкуренцию в сфере здравоохранения есть и достаточное количество «смешанных вариантов» определения и назначения конкуренции в отрасли. Так, например, в работе И.Н. Баранова обобщаются отдельные модели предоставления услуг здравоохранения, заключающиеся в различных сочетаниях частного и общественного финансирования и производства медицинских услуг [Баранов, 2010, c. 21].

Помимо отечественного опыта развития конкуренции в здравоохранении нельзя не затронуть зарубежную практику, в частности опыт США, которые характеризуются наиболее значительными масштабами конкуренции в рассматриваемой отрасли. Однако многолетний опыт функционирования здравоохранения позволяет и исследователям этой страны выделить проблемы в процессе внедрения принципов конкуренции. Уже в 2004 г. М.Е. Портер и Е. Теисберг отмечали, что основная цель и назначение конкуренции, традиционное для стандартного рынка, в сфере здравоохранения не реализуется. Снижение затрат, ожидаемое в результате использования конкурентных механизмов, в здравоохранении принимает форму смещения и переноса их на пациента. «Выгоды для одного 
участника системы приходят за счет других с одновременным ростом дополнительных административных расходов» [Porter et al., 2004]. В Соединенных Штатах конкуренция обеспечивается за счет развитой системы страхования, однако, в отличие от отечественной системы, страховые взносы существенно выше, так как обеспечивают покрытие затрат по большему количеству медицинских случаев, что значительно повышает сумму страхового взноса и ограничивает количество обладателей страховки [Dayaratna, 2013]. В данном случае результат развития конкуренции на рынке медицинских услуг вступает в противоречие с целями и приоритетами общества.

В отечественной науке, несмотря на имеющиеся теоретические исследования в области здравоохранения, можно констатировать отсутствие комплексного подхода к оценке конкуренции и ее развитию на региональных рынках медицинских услуг, который мог бы быть использован на практике.

На сегодняшний момент практическая реализация установки на развитие конкуренции на социально значимых рынках заключаются в проведении ежегодного мониторинга, разработке и реализации Плана мероприятий (Дорожной карты) по развитию конкуренции. Мониторинг представляет собой электронное анкетирование потребителей услуг, включающее вопросы, которые касаются удовлетворенности отдельными параметрами конкуренции: уровнем цен, возможностью выбора, качеством услуг.

На наш взгляд, подход, основанный лишь на субъективных оценках потребителей, не может дать объективной картины развития конкуренции на рынке. Существующая ситуация требует разработки и реализации методов оценки и развития конкуренции на рынке медицинских услуг, использующих реальные механизмы и адекватные показатели при учете секторов рынка, на которых вообще возможно развитие конкуренции.

\section{Методика}

В рамках исследования, проводимого по заказу Министерства экономического развития Рязанской области в течение 2016-2018 гг.
[Мониторинг ... , 2018, с. 7-75; Состояние..., 2018, с. 9-148], была предложена методика оценки уровня конкуренции [Разработка ..., 2016, с. 34-35]. Суть методики сводится к использованию двух групп показателей (объективных и субъективных) и формированию интегральной оценки на основе суммирования баллов по каждому из них. Некоторые коррективы, внесенные в методику за три года исследований, позволили представить окончательный вариант формулы расчета в следующем виде:

$$
A=\sum_{i} O_{i}+\sum_{j} S_{j},
$$

где $A$ - интегральная оценка уровня конкуренции на рынке; $O_{i}-$ величина $i$-го показателя из группы объективных показателей, выраженная в баллах; $S_{j}-$ величина $j$-го показателя из группы субъективных показателей, выраженная в баллах.

По итогам расчетов каждый рынок можно охарактеризовать в соответствии с диапазоном, в котором оказалось значение интегральной оценки:

- слабая конкуренция - значение интегральной оценки составило от 4 до 10,6 балла;

- умеренная конкуренция - с 10,7 до 17,3 балла;

- развитая конкуренция - с 17,4 до 24 баллов.

В таблице 1 приведены балльные оценки конкуренции на рынке медицинских услуг по субъективным и объективным показателям.

Полученные оценки свидетельствуют о том, что рассматриваемый рынок попадает в категорию рынков со слабой конкуренцией в 2016-2018 годах. В первый год исследования значение интегральной оценки находилось на границе диапазонов «слабая конкуренция» - «умеренная конкуренция». Среди частных оценок отмечается падение удовлетворенности параметрами конкуренции на фоне количественного роста медицинских организаций (см. табл. 2).

Так, например, удовлетворенность населения параметрами «цена» и «качество» за рассматриваемый период снизилась с $34 \%$ и $43 \%$ до $29 \%$ и $38 \%$ соответственно. По возможности выбора доля «удовлетворенных» потребителей выросла всего на 1 \%. 


\section{Оценка уровня конкуренции на рынке медицинских услуг по субъективным и объективным показателям}

\begin{tabular}{|c|c|c|c|c|}
\hline \multirow[t]{2}{*}{ Показатель } & \multicolumn{3}{|c|}{$\begin{array}{c}\text { Балльные оценки уров- } \\
\text { ня конкуренции }\end{array}$} & \multirow[t]{2}{*}{ Пояснения к присвоению оценок } \\
\hline & 2016 г. & 2017 г. & 2018 г. & \\
\hline \multicolumn{5}{|c|}{ Объективные показатели } \\
\hline $\begin{array}{l}\text { Число организаций, конкурирующих на } \\
\text { рынке }\end{array}$ & 2 & 2 & 2 & $\begin{array}{l}1 \text { балл - менее } 4 ; 2 \text { балла - от } 4 \text { до 6; } 3 \text { бал- } \\
\text { ла - больше } 6\end{array}$ \\
\hline $\begin{array}{l}\text { Доля государственных и муниципаль- } \\
\text { ных предприятий на рынке (в объеме } \\
\text { оказываемых услуг), \% }\end{array}$ & 1 & 1 & 1 & $\begin{array}{l}1 \text { балл - более } 70 \% ; 2 \text { балла - от } 50 \text { до } \\
70 \% ; 3 \text { балла - менее } 50 \%\end{array}$ \\
\hline $\begin{array}{l}\text { Изменение количества организаций на } \\
\text { рынке за последние } 3 \text { года (уменьшение } \\
\text { или увеличение), \% }\end{array}$ & 1 & 1 & 1 & $\begin{array}{l}1 \text { балл - до } 5 \% \text {; } 2 \text { балла - от } 5 \text { до } 25 \% \text {; } \\
3 \text { балла - более } 25 \%\end{array}$ \\
\hline Итого & 4 & 4 & 4 & - \\
\hline \multicolumn{5}{|c|}{ Субъективные показатели* } \\
\hline $\begin{array}{l}\text { Оценка количества организаций, рабо- } \\
\text { тающих на целевых рынках }\end{array}$ & 1,46 & 1,42 & 1,47 & $\begin{array}{l}\text { Избыточно - } 3 \text { балла; достаточно - } 2 \text { балла; } \\
\text { мало - } 1 \text { балл; нет совсем - } 0 \text { баллов; за- } \\
\text { трудняюсь ответить - вариант ответа не } \\
\text { рассматривается }\end{array}$ \\
\hline $\begin{array}{l}\text { Удовлетворенность уровнем цен на } \\
\text { продукцию на целевых рынках }\end{array}$ & 0,99 & 0,93 & 0,86 & \multirow{3}{*}{$\begin{array}{l}\text { Удовлетворен - } 3 \text { балла; скорее удовлетво- } \\
\text { рен - } 2 \text { балла; скорее неудовлетворен - } \\
1 \text { балл; неудовлетворен - } 0 \text { баллов; затруд- } \\
\text { няюсь ответить - вариант ответа не рас- } \\
\text { сматривается }\end{array}$} \\
\hline $\begin{array}{l}\text { Удовлетворенность качеством продук- } \\
\text { ции на целевых рынках }\end{array}$ & 1,22 & 1,07 & 1,04 & \\
\hline $\begin{array}{l}\text { Удовлетворенность возможностью вы- } \\
\text { бора продукции на целевых рынках }\end{array}$ & 1,23 & 1,09 & 1,12 & \\
\hline $\begin{array}{l}\text { Изменение количества поставщиков } \\
\text { продукции на целевых рынках в тече- } \\
\text { ние установленного периода }\end{array}$ & 1,76 & 1,72 & 1,72 & $\begin{array}{l}\text { Снизилось - } 1 \text { балл; не изменилось - } 2 \text { бал- } \\
\text { ла; увеличилось - } 3 \text { балла; затрудняюсь от- } \\
\text { ветить - вариант ответа не рассматривается }\end{array}$ \\
\hline Итого & 6,66 & 6,23 & 6,21 & - \\
\hline Интегральная оченка уровня конкуренциии & 10,66 & 10,23 & 10,21 & - \\
\hline
\end{tabular}

Примечание. Составлено автором. $* S_{j}$ определяется по формуле $S_{j}=\sum D_{j k} B_{j k}$, где $B_{j k}-$ оценка $j$-го показателя в баллах $k ; D_{j k}$ - доля респондентов, выбравших при оценке $j$-го показателя вариант $k$.

Таблица 2

Удовлетворенность потребителей медицинскими услугами в 2016 и 2018 гг.

\begin{tabular}{|l|c|c|c|c|c|c|}
\hline \multicolumn{1}{|c|}{ Показатель } & \multicolumn{2}{c|}{ Цена } & \multicolumn{2}{c|}{ Качество } & \multicolumn{2}{c|}{$\begin{array}{c}\text { Возможность } \\
\text { выбора }\end{array}$} \\
\cline { 2 - 8 } & 2016 г. & 2018 г. & 2016 г. & 2018 г. & 2016 г. & 2018 г. \\
\hline $\begin{array}{l}\text { Доля респондентов, выбравших ответы } \\
\text { «удовлетворен» и «скорее удовлетворен» } \\
\text { в общем количестве опрошенных, \% }\end{array}$ & 34 & & & & & \\
\hline
\end{tabular}

Примечание. Составлено автором.

На основе данных ежегодного мониторинга в соответствии со стандартом должен быть разработан и реализован План мероприятий (Дорожная карта) развития конкуренции. Мероприятия, входящие в Дорожную карту Рязанской области [Об утверждении плана ..., 2015], обобщены в таблице 3.

Анализ мероприятий по развитию конкуренции в Рязанском регионе свидетельствует о том, что основным инструментом развития конкуренции является рост коли- чества организаций: офисов врачей общей практики, организаций, финансируемых из средств Фонда обязательного медицинского страхования (далее - ФОМС). Однако только обеспечение роста количества организаций не может повлиять на развитие конкуренции на рынке. Необходимо обеспечить не большое количество участников рынка, а рост и разнообразие оказываемых услуг. Только в этом случае можно говорить о конкуренции на рынке. 
Мероприятия, используемые органами власти Рязанской области для развития конкуренции на рынке медицинских услуг в 2016-2018 гг.

\begin{tabular}{|c|c|c|c|}
\hline \multirow{2}{*}{$\begin{array}{c}\text { Запланированные мероприятия } \\
\text { по развитию конкуренции }\end{array}$} & \multicolumn{3}{|c|}{ Итоги реализации мероприятий } \\
\hline & 2016 г. & 2017 г. & 9 мес. 2018 г. \\
\hline $\begin{array}{l}\text { Включение негосударственных (немуниципаль- } \\
\text { ных) медицинских организаций в перечень ме- } \\
\text { дицинских организаций, участвующих в реали- } \\
\text { зации программы государственных гарантий } \\
\text { бесплатного оказания гражданам медицинской } \\
\text { помощи на территории Рязанской области, кол- } \\
\text { во организаций }\end{array}$ & 32 & 36 & 37 \\
\hline $\begin{array}{l}\text { Создание офисов общей врачебной практики, } \\
\text { кол-во офисов }\end{array}$ & $\begin{array}{l}22(17-\text { в рай- } \\
\text { онах области; } \\
5-\text { в г. Рязани) }\end{array}$ & $\begin{array}{l}25(20-\text { в } \\
\text { г. Рязани })\end{array}$ & бласти; 5 - в \\
\hline $\begin{array}{l}\text { Создание диализных отделений на территории } \\
\text { Рязанской области }\end{array}$ & \multicolumn{3}{|c|}{$\begin{array}{l}\text { Создан и функционирует диализный центр ООО «Фрезениус», } \\
\text { который был построен в рамках заключенного в } 2012 \text { г. со- } \\
\text { глашения между правительством Рязанской области и компа- } \\
\text { нией «Fresenius Medical Care Deutschland GmbH» }\end{array}$} \\
\hline $\begin{array}{l}\text { Обеспечение возможности проведения анкети- } \\
\text { рования на официальном сайте в сети Интернет } \\
\text { для организации независимой оценки качества } \\
\text { оказания услуг медицинскими организациями в } \\
\text { амбулаторных и стационарных условиях }\end{array}$ & \multicolumn{3}{|c|}{$\begin{array}{l}\text { Обеспечена возможность проведения анкетирования на офици- } \\
\text { альных сайтах медицинских организаций и сайте Минздрава } \\
\text { Рязанской области в информационно-телекоммуникационной } \\
\text { сети Интернет для организации независимой оценки качества } \\
\text { оказания услуг медицинскими организациями }\end{array}$} \\
\hline
\end{tabular}

Примечание. Составлено автором.

Анализ целевых показателей, заложенных в Плане развития конкуренции (см. табл. 4), свидетельствует о заведомо низких запланированных темпах роста используемых индикаторов. Так, за три года реализации плана ожидается увеличение доли расходов Территориального фонда обязательного медицинского страхования (далее - ТФОМС) на финансирование негосударственных учреждений с $3,1 \%$ до 3,2 \%, рост доли негосударственных учреждений в общем количестве медицинских организаций - на $2 \%$, количества офисов врачей общей практики - с 6 до 8. На основе приведенных значений данных показателей создается впечатление, что они подобраны не из цели развития конкуренции, а исходя из возможности их достижения при незначительных усилиях.

Анализ деятельности органов власти в Рязанском регионе свидетельствует о формальном применении программно-целевого подхода, при котором заложенные изменения значений сформулированных показателей не дают ощутимых результатов на практике. Несмотря на достижение плановых значений показателей, степень удовлетворенности уровнем конкуренции на рынке, да и самими услугами, падает. Это свидетельствует о том, что мероп- риятия и показатели выбраны не из целей улучшения состояния рынка, а, скорее, исходя из соображений достижимости показателей.

\section{Результаты и обсуждение}

Специфика рынка медицинских услуг накладывает определенные ограничения на развитие конкуренции. Рынок медицинских услуг как область социальной сферы имеет некоторые особенности, в частности:

1. Социальная направленность услуг, обусловливающая необходимость государственного регулирования отрасли в части стандартизации услуг, лицензирования деятельности медицинских организаций, обеспечения населения возможностями получения медицинской помощи вблизи мест их проживания.

2. Задействование Фонда обязательного медицинского страхования как посредника в оплате услуг. С точки зрения правительства РФ, средства фонда должны стать основным стимулом для конкуренции коммерческих медицинских организаций.

3. Наличие значительной доли государственных организаций - поставщиков услуг. Снижение этой доли возможно, но не на все виды услуг. 


\section{Целевые показатели развития конкуренции на рынке медицинских услуг Рязанской области в 2016-2018 гг.}

\begin{tabular}{|c|c|c|c|c|c|c|}
\hline \multirow{3}{*}{ Целевой показатель } & \multicolumn{6}{|c|}{ Значение целевого показателя } \\
\hline & \multicolumn{2}{|c|}{2016 г. } & \multicolumn{2}{|c|}{2017 г. } & \multicolumn{2}{|c|}{2018 г. } \\
\hline & План & Факт & План & Факт & План & План \\
\hline $\begin{array}{l}\text { Доля затрат на медицинскую помощь по обяза- } \\
\text { тельному медицинскому страхованию, оказан- } \\
\text { ную негосударственными (немуниципальными) } \\
\text { медицинскими организациями, в общих расхо- } \\
\text { дах на выполнение территориальных программ } \\
\text { обязательного медицинского страхования, \% }\end{array}$ & 3,1 & 3,8 & 3,1 & 4,5 & 3,2 & 3,2 \\
\hline $\begin{array}{l}\text { Доля негосударственных (немуниципальных) } \\
\text { медицинских организаций, оказывающих меди- } \\
\text { цинскую помощь по обязательному медицин- } \\
\text { скому страхованию в рамках выполнения терри- } \\
\text { ториальных программ обязательного медицин- } \\
\text { ского страхования, \% }\end{array}$ & 32 & 34,4 & 33 & 37,1 & 34 & 34 \\
\hline $\begin{array}{l}\text { Открытие офисов общей врачебной практики } \\
\text { (в том числе с применением механизмов госу- } \\
\text { дарственно-частного партнерства), ед. }\end{array}$ & 6 & 4 & 8 & 6 & 8 & 8 \\
\hline
\end{tabular}

\section{Примечание. Составлено автором.}

На рисунке 1 приведена структура рынка медицинских услуг Рязанской области по видам собственности организаций в 2018 году. В рамках программы обязательного медицинского страхования (далее - ОМС) в прошедшем году работало 37 организаций, однако это всего $16 \%$ всех коммерческих организаций.

Рассмотрение существующих на данный момент в регионе коммерческих медицинских организаций позволяет утверждать, что основной профиль их деятельности сводится к амбулаторной помощи, проведению анализов. Отдельным сектором рынка, в котором уже развита конкуренция, можно считать стоматологию. Отчасти это обусловлено сравни- тельно низкими издержками вхождения на рынок. Организация перечисленных видов медицинской помощи не требует значительных затрат. Кроме того, существенным фактором выступает отсутствие ощутимых изменений в нормативном регулировании данных видов медицинской помощи. Ярким примером влияния последнего фактора является рынок услуг пластической хирургии. В связи с последними изменениями в нормативно-правовой базе этого вида медицинской помощи спектр деятельности большинства клиник пластической хирургии страны резко сократился, сведясь к консультированию и послеоперационному обслуживанию. Соответственно, уро-

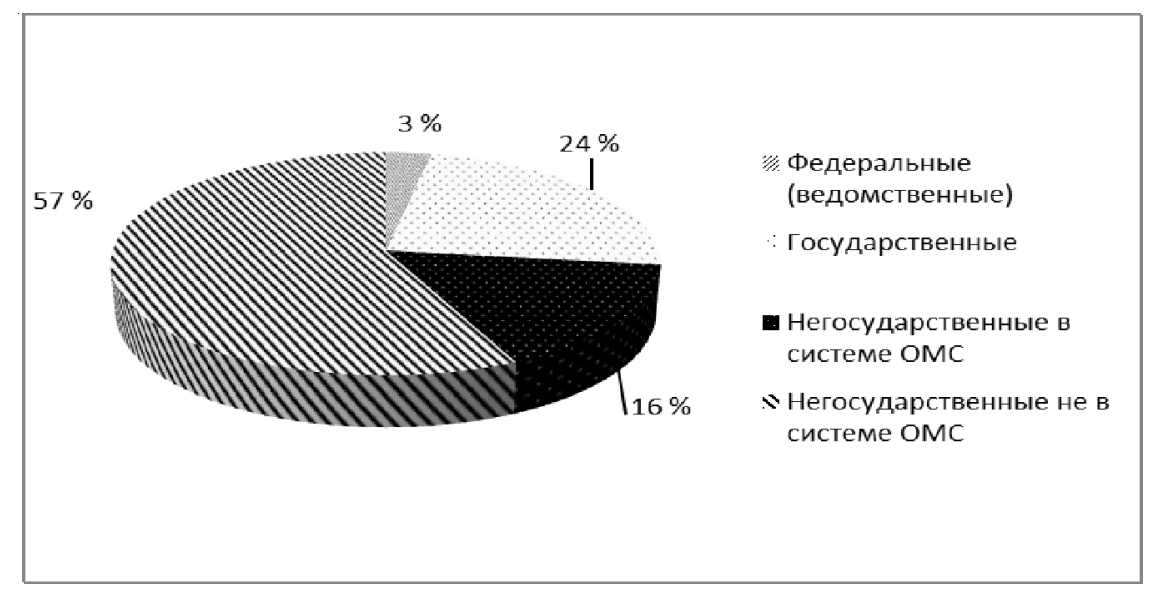

Рис. 1. Структура рынка медицинских услуг Рязанской области по видам собственности организаций в 2018 г. 
вень конкуренции на рынках, по крайней мере региональных, в данном сегменте существенно снизился.

Развитие конкуренции на рынке медицинских услуг региона должно осуществляться с использованием системного подхода и решать следующие задачи:

- оптимизация ассортимента медицинских услуг на территории региона;

- снижение административных барьеров вхождения на рынок;

- обеспечение прозрачности и упрощение механизма финансирования организаций из средств ФОМС;

- формирование модели функционирования системы здравоохранения, предполагающей использование конкурентных механизмов, а не перевод отрасли полностью на рыночные условия работы.

Социальная направленность рассматриваемой сферы требует от государства гарантий качества оказания необходимой медицинской помощи в регионе. Без определенного государственного регулирования эта сфера функционировать не может, поэтому первая задача региональных органов власти - обеспечить условия для формирования широкого ассортимента медицинских услуг. Для этого целесообразно проведение инвентаризации медицинских услуг, оказываемых в регионе, определение проблемных видов услуг и районов отсутствия необходимых видов помощи.

Для стимулирования роста количества клиник «нужных» направлений следует проанализировать административные барьеры. На сегодняшний день административные барьеры развития рынка медицинских услуг заключаются в следующем:

1. Лицензирование. К моменту лицензирования у соискателя лицензии должно быть оборудование, помещение и персонал. При этом деятельность еще не ведется. Срок ожидания лицензии составляет 45 рабочих дней, ее стоимость - 7500 руб. Таким образом, не имея возможности получения доходов, медицинская организация в процессе лицензирования вынуждена оплачивать аренду помещения, оборудования, коммунальные услуги в течение 1,5 месяца в случае полной корректности и правильности подготовки документов на лицензирование.
2. Организационные проблемы работы в системе ОМС. Включение медицинской организации в систему финансирования из ФОМС предполагает выполнение жестких требований как к процессу оказания медицинской помощи, так и к последующей отчетности перед фондом. Наряду с фиксированными тарифами за каждую услугу, фондом установлены штрафные санкции за нарушения в работе, в частности за размещение информации на сайте организации, в информировании населения, назначениях препаратов. Эти условия, призванные обеспечить качество оказания медицинской помощи, создают непреодолимые препятствия для начинающих малопрофильных клиник с невысоким потоком пациентов. Необходимость соблюдения всех выставленных требований заставляет клиники отказываться от системы финансирования из ФОМС и выстраивать отношения напрямую с пациентами.

3. Финансовые проблемы работы в системе ОМС. На сегодняшний момент система финансирования за счет средств ФОМС не предполагает получение прибыли, что противоречит цели организации коммерческой клиники. Кроме того, тарифы абсолютно не связаны с качеством оказания услуги, которое в частных организациях, как правило, выше в связи с использованием более современного оборудования. При этом при работе в системе ОМС между оплатой и выпиской пациента существует значительный временной промежуток.

Все перечисленные особенности и проблемы должны лечь в основу разработки модели здравоохранения, построенной не на формировании конкурентного рынка медицинских услуг, а на использовании конкурентных механизмов в тех аспектах деятельности организаций, где это необходимо. При этом переходный период должен четко контролироваться государством. Модель функционирования системы здравоохранения в ближайшей перспективе сформирована на рисунке 2 .

Представленная модель включает в себя разные уровни оказания медицинской помощи: от амбулаторно-поликлинической помощи до круглосуточного стационара и высокотехнологической медицинской помощи. Градация этих уровней построена по принци- 


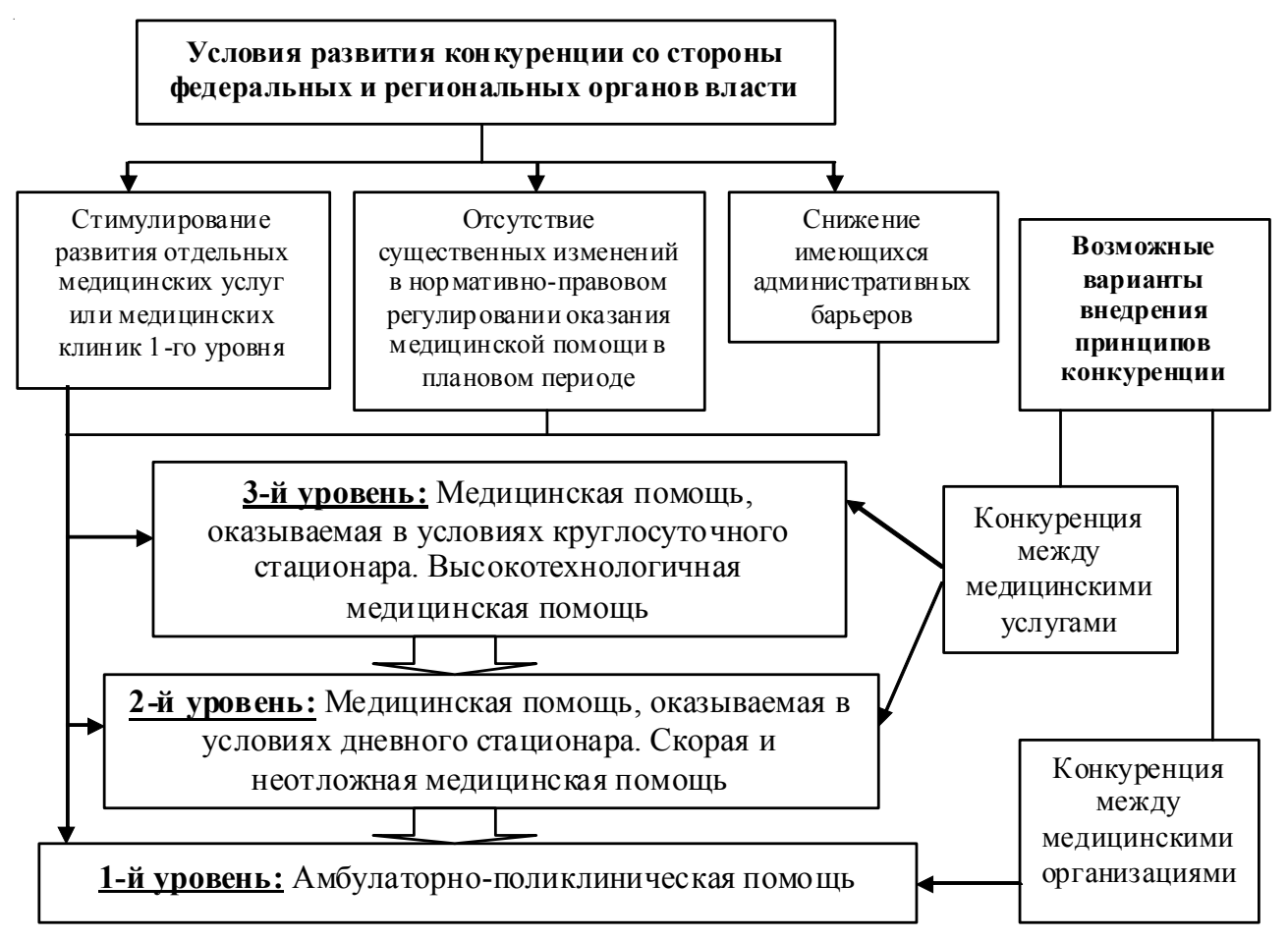

Рис. 2. Модель развития конкуренции на рынке медицинских услуг

пу сложности и затратности организации предоставления медицинской помощи с целью развития конкурентных механизмов в отрасли. Внедрение принципов конкуренции логичнее всего начать с первого уровня системы. Как ранее было сказано, частично это уже сделано: во всех регионах наряду с государственными поликлиниками существуют частные врачебные практики, коммерческие медицинские учреждения и т. д. Этот уровень системы здравоохранения имеет следующие особенности:

- сравнительно небольшие затраты на организацию работы;

- сравнительно низкая стоимость услуг;

- стандартность большинства услуг по содержанию;

- стабильный поток пациентов по сравнению с другими уровнями системы.

Все эти особенности обусловливают достаточно простое внедрение конкурентных механизмов при условии снижения имеющихся административных барьеров. Например, на сегодня стала очевидной неприживаемость принципов страховой медицины в коммерческом секторе первого звена. Об этом свидетельствует низкая доля клиник, функционирующих в рамках системы ОМС, низкие тари- фы оплаты медицинской помощи на этом уровне в сочетании со значительными объемами контроля со стороны ФОМС. Поэтому заявления правительства РФ о развитии конкуренции в медицине путем включения коммерческих клиник в систему финансирования из фонда не представляются реализуемыми. Для этого уровня медицинской помощи целесообразны сокращения объемов страховой медицины и стимулирование развития клиник, работающих напрямую с пациентом. В качестве механизмов такого стимулирования могут стать: гранты на организацию медицинских клиник, налоговые каникулы при внедрении определенных видов медицинских услуг или в первые годы работы, имущественная и правовая поддержка начинающих клиник. Перечисленные меры во многом уже имеют успешный опыт применения в других сферах и могут быть распространены на медицинские организации.

Второй и третий уровни системы здравоохранения отличаются трудоемкостью и существенными затратами в организации. На этих уровнях образование конкурирующих между собой клиник существенно осложняется. И если в некоторых регионах существуют альтернативные станции скорой помощи 
или клиники отдельных профилей, функционирующие в коммерческом формате, то альтернатива районной или областной больницы вряд ли возможна. Соответственно, на этих уровнях вероятнее всего конкуренция не между организациями, а между отдельными их услугами. Здесь уже целесообразно внедрение принципов страховой медицины: тарифы на услуги в рамках рассматриваемых уровней со стороны ФОМС существенно выше, чем на амбулаторно-поликлиническую помощь, и клиники, используя эти механизмы, должны иметь возможность получения некоторого дохода и покрытия своих расходов. Со стороны государства в качестве стимулирующих механизмов здесь должны превалировать мероприятия, направленные на развитие отдельных видов услуг в рамках коммерческой медицины, а также упрощение работы с ФОМС.

\section{Выводы}

Внедрение принципов конкуренции на всех обозначенных уровнях системы здравоохранения должно сопровождаться созданием уже описанных ранее условий, реализуемых органами власти (стимулирование развития отдельных видов медицинских услуг или коммерческих клиник, снижение имеющихся административных барьеров и стабильность нормативно-правовой базы, регулирующей оказание услуг).

Естественно, представленная модель сформирована в общем теоретическом виде и нуждается в доработке и учете множества нюансов функционирования отдельных направления медицинской помощи. Однако данное описание может стать началом перевода рассматриваемой сферы на конкурентные принципы на основе комплексного учета интересов всех заинтересованных сторон, а не существующих на данный момент директивных государственных новшеств с сомнительными перспективами применения.

\section{СПИСОК ЛИТЕРАТУРЫ}

Баранов, И. Н. Конкуренция в сфере здравоохранения / И. Н. Баранов. - СПб. : ВШМ СПбГУ, 2010. - (Научные доклады ; № 1 (R)-2010).
Мониторинг состояния и развития конкурентной среды на рынках товаров работ и услуг Рязанской области : отчет о НИР / Рязан. гос. радиотехн. ун-т ; рук. Бычкова Н. А. ; исполн.: Горбова О. Ю. [и др.]. - Рязань, 2018. $-81 \mathrm{c}$.

Об основных направлениях государственной политики по развитию конкуренции : указ Президента РФ от 21.12.2017 № 618. - Доступ из справ.-правовой системы «КонсультантПлюс».

Об утверждении плана мероприятий («дорожная карта») по содействию развитию конкуренции в Рязанской области : распоряжение губернатора Рязанской области от 29.12.2015 № 454-рг. - Доступ из справ.-правовой системы «КонсультантПлюс».

Разработка методики оценки состояния конкуренции на региональных рынках / С. В. Перфильев [и др.] // Научный результат. Экономические исследования. - 2016. - Т. 2, № 4. - С. 32 37. - DOI: 10.18413/2409-1634-2016-2-4-32-37.

Селезнев, В. Д. Проблемы конкуренции в российском здравоохранении / В. Д. Селезнев, С. Д. Волков // Научный журнал НИУ ИТМО. Серия «Экономика и экологический менеджмент». - 2016. - № 1. - С. 112-117. - Электрон. текстовые дан. - Режим доступа: https:// cyberleninka.ru/article/n/problemy-konkurentsiiv-rossiyskom-zdravoohranenii (дата обращения: 20.03.2019). - Загл. с экрана.

Состояние конкуренции в муниципальных районах и городских округах Рязанской области : отчет о НИР / Рязан. гос. радиотехн. ун-т ; рук. Горбова О. Ю. ; исполн.: Бычкова Н. А. [и др.]. - Рязань, 2018. - 152 с.

Стандарт развития конкуренции в субъектах Российской Федерации : распоряжение Правительства Российской Федерации от 05.09.2015 № 1738-p. - Доступ из справ.-правовой системы «КонсультантПлюс».

Тогунов, И. А. Теория управления рынком медицинских услуг : монография / И. А. Тогунов. Владимир : Собор, 2007. - 308 c.

Dayaratna, K. Competitive Markets in Health Care: The Next Revolution. - Aug. 19, 2013. - Electronic text data. - Mode of access: https://www. heritage.org/health-care-reform/report/ competitive-markets-health-care-the-nextrevolution. - Title from screen.

Porter, M. Redefining Competition in Health Care / M. Porter, E. Teisberg // Harvard Business Review. - 2004. - June. - Electronic text data. Mode of access: https://hbr.org/2004/06/ redefining-competition-in-health-care. - Title from screen. 


\section{REFERENCES}

Baranov I.N. Konkurentsiya v sfere zdravookhraneniya [Competition in Health Care]. Saint Petersburg, VShM SPbGU, 2010. (Nauchnye doklady [Scientific Reports]; no. 1 (R)-2010).

Bychkova N.A., Gorbova O.Yu. Monitoring sostoyaniya i razvitiya konkurentnoy sredy na rynkakh tovarov rabot $i$ uslug Ryazanskoy oblasti [Monitoring of the State and Development of the Competitive Environment in the Markets of Goods and Services of Ryazan Region]. Ryazan, Ryazanskiy gosudarstvennyy radiotekhnicheskiy universitet, 2018. $81 \mathrm{p}$.

Ob osnovnykh napravleniyakh gosudarstvennoy politiki po razvitiyu konkurentsii : ukaz Prezidenta RF ot 21.12.2017 № 618 [On the Main Directions of the State Policy on Development of Competition. Decree of the President of the Russian Federation of December 21, 2017 no. 618]. Access from Reference Legal System "ConsultantPlus".

$\mathrm{Ob}$ utverzhdenii plana meropriyatiy («dorozhnaya karta») po sodeystviyu razvitiyu konkurentsii v Ryazanskoy oblasti : rasporyazhenie gubernatora Ryazanskoy oblasti ot 29.12.2015 № 454-rg. [On Approving the Action Plan ("Road Map") on Assistance to Development of Competition in Ryazan Region. Order of the Governor of Ryazan Region of December 29, 2015 no. 454- рг]. Access from Reference Legal System "ConsultantPlus".

Perfilyev S.V., et al. Razrabotka metodiki otsenki sostoyaniya konkurentsii na regionalnykh rynkakh [Development of Methods for Assessing the State of Competition in Regional Markets]. Nauchnyy rezultat. Ekonomicheskie issledovaniya [Research Result. Economic
Research], 2016, vol. 2, no. 4, pp. 32-37. DOI: 10.18413/2409-1634-2016-2-4-32-37.

Seleznev V.D., Volkov S.D. Problemy konkurentsii v rossiyskom zdravookhranenii [Competition Problems in Russian Health Care]. Nauchnyy zhurnal NIU ITMO. Seriya "Ekonomika $i$ ekologicheskiy menedzhment» [Scientific journal NRU ITMO. Series "Economics and Environmental Management"], 2016, no. 1, pp. 112-117. URL: https://cyberleninka.ru/article/ $\mathrm{n} /$ problemy-konkuren tsii-v-rossiyskomzdravoohranenii (accessed 20 March 2019).

Gorbova O.Yu., Bychkova N.A. Sostoyanie konkurentsii $v$ munitsipalnykh rayonakh $i$ gorodskikh okrugakh Ryazanskoy oblasti [State ofCompetition in Municipal Districts and Urban Districts of Ryazan Region]. Ryazan, 2018. 152 p.

Standart razvitiya konkurentsii v subyektakh Rossiyskoy Federatsii : rasporyazhenie Pravitelstva Rossiyskoy Federatsii ot 05.09.2015 № 1738-r. [Standard of Development of Competition in Subjects of the Russian Federation. Order of the Government of the Russian Federation of September 5, 2015 no. 1738-p]. Access from Reference Legal System "ConsultantPlus".

Togunov I.A. Teoriya upravleniya rynkom meditsinskikh uslug : monografiya [Theory of Managing the Medical Service Market. Monograph]. Vladimir, Sobor Publ., 2007. 308 p.

Dayaratna K. Competitive Markets in Health Care: The Next Revolution. August 19, 2013. URL: https:/www.heritage.org/health-care-reform/ report/competitive-markets-health-care-thenext-revolution.

Porter M., Teisberg E. Redefining Competition in Health Care. Harvard Business Review, 2004, June. URL: https://hbr.org/2004/06/redefining-competitionin-health-care.

\section{Information about the Author}

Olga Yu. Gorbova, Candidate of Sciences (Economics), Associate Professor, Department of State, Municipal and Corporate Governance, Ryazan State Radio Engineering University, Gagarina St., 59/1, 390005 Ryazan, Russian Federation, odina-olga@yandex.ru, https://orcid.org/0000-0002-9210-2236

\section{Информация об авторе}

Ольга Юрьевна Горбова, кандидат экономических наук, доцент кафедры государственного, муниципального и корпоративного управления, Рязанский государственный радиотехнический университет, ул. Гагарина, 59/1, 390005 г. Рязань, Российская Федерация, odina-olga@yandex.ru, https://orcid.org/0000-0002-9210-2236 